\title{
The friction-free weighted price contribution
}

\author{
David Abad $^{\mathrm{a}, *}$, Roberto Pascual ${ }^{\mathrm{b}, 1}$ \\ a Departamento Economía Financiera y Contabilidad, Universidad de Alicante, Crta. San Vicente del Raspeig s/n, 03690 San Vicente del Raspeig, Alicante, Spain \\ b Departament d'Economia de l'Empresa, Universitat de les Illes Balears, Crta. De Valldemossa, km. 7.5, 07122 Palma de Mallorca, Illes Balears, Spain
}

\section{A R T I C L E I N F O}

Article history:

Received 7 February 2014

Received in revised form 27 October 2014

Accepted 30 November 2014

Available online 12 December 2014

\section{JEL classification:}

G10

G14

Keywords:

Weighted price contribution

Trading frictions

Stealth trading

Aggressiveness

Market microstructure

\begin{abstract}
A B S T R A C T
We introduce a methodology to obtain friction-free estimates of Barclay and Warner's (1993) Weighted Price Contribution (WPC). With this new approach, we verify recent simulation results suggesting that trading frictions may severely bias the WPC approach. We use high frequency data from a European electronic order-driven market to show that frictions generate a sizable downward bias in the WPC of non-aggressive small-size trades. The bias increases in periods of significant price discovery, and is due to both bid-ask bounce and serial correlation in the quotemidpoint changes. We show that our results extend to the US case.
\end{abstract}

(c) 2014 Elsevier Inc. All rights reserved.

\section{Introduction}

It is widely accepted that private information in financial markets is revealed through trading and that information-motivated traders, in an attempt to delay the full revelation of their information, look for ways to conceal their trading intentions. ${ }^{2}$ Barclay and Warner (1993) (hereafter, BW93) study the trade-size choices of strategic informed traders. They introduce the Weighted Price Contribution (WPC) approach to test the so-called stealth trading hypothesis (STH). ${ }^{3}$ The WPC measures how much of a stock's cumulative price change over a given time period is attributable to trades grouped into particular trade-size categories. The WPC has become the standard tool to study strategic fragmentation of orders, and is frequently used as an alternative to parametric methods to measure price leadership (e.g., Hasbrouck, 1995). ${ }^{4}$

The WPC assumes that price changes are primarily information-driven. The existence of a noisy component in price changes, one of the milestones of market microstructure research (e.g., Hasbrouck, 2007), challenges the WPC approach. BW93 (p. 300 ) state that

\footnotetext{
* Corresponding author. Tel.: + $34965903400 \times 3158$.

E-mail addresses: goliat@ua.es (D. Abad), rpascual@uib.es (R. Pascual).

1 Tel.: + 34971171329 .

${ }^{2}$ For example, strategic informed traders may obscure their positions by breaking up large trades and spreading them through time (Kyle, 1985); trading when liquidity-motivated volume is high (Admati \& Pfleiderer, 1988); acting as passive liquidity providers (Harris, 1998, and Kaniel \& Liu, 2006) or using undisclosed limit orders (e.g., Bessembinder, Panayides, \& Venkataraman, 2009).

${ }^{3}$ The STH reads: "[...] if informed traders concentrate their trades in medium sizes, and stock-price movements are mainly due to private information revealed through these investors' trades, then most of the stocks cumulative price change will take place on medium size trades" (BW93, p. 282).

4 A few examples include Cao, Ghysels, and Hatheway (2000), Huang (2002), Barclay and Hendershott (2003, 2008), and Ellul, Shin, and Tonks (2005).
} 
the WPC should allow for trading frictions so long as the temporary components of the price change are not systematic. Some recent studies cast some doubt on their claim. van Bommel (2011) studies the statistical properties of the WPC using simulated daily series. He finds that the WPC is an inconsistent and biased estimator of price discovery when prices deviate from a martingale process due to serial correlation. Likewise, Wang and Yang (2010) uses low-frequency data to show that the WPC approach deviates from the information share approach of Hasbrouck (1995) in the presence of return serial correlation. At best, these studies stress the need to control for trading frictions when implementing the WPC approach.

In this paper, we propose a simple procedure to obtain friction-free WPC estimates using high (trade-by-trade) frequency data. The procedure consists of three steps: firstly, we replace trade prices by quote midpoints to control for the bid-ask bounce; secondly, we apply standard time series techniques to extract the friction-related dynamics in the quote-midpoint changes; thirdly, we use the estimated friction-unrelated component of the quote-midpoint changes to obtain the friction-free WPC estimate ( $\overline{\text { WPC }}) .{ }^{5}$ By means of our WPC estimates, we provide empirical evidence of the friction-related bias in the standard WPC when applied to high-frequencydata.

We begin by reporting a significant friction-driven downward bias in the standard WPC of small-size trades for the most liquid and active stocks of the electronic order-driven platform of the Spanish Stock Exchange (SSE) between July 2000 and December 2006 . Ignoring trading frictions, the daily WPC of medium-size trades is $83 \%$, while the daily WPC of small-size trades is $-1.6 \%$. In contrast, the $\overline{\text { WPC }}$ of medium ( small) size trades is 55.4\% (37.1\%). Next, we test if this friction-related downward bias for small-size trades increases with the likelihood of information-motivated trading. As we restrict ourselves to days with open-to-close returns above $1 \%$, the downward bias of the small-size trades increases, from $-38.7 \%$ to $-72.71 \%$. We show that negative WPCs for small size trades, which are frequently taken as evidence of underperformance by retail traders, are rather due to trading frictions. We also document that this friction-related bias can significantly distort formal tests of the STH.

We provide some insights on the sources of the friction-related WPC bias. Firstly, we estimate that 85.6\% of the daily WPC downward bias for small-size trades is driven by the bid-ask bounce, but serial correlation significantly adds to the bias. So, the frictionrelated bias of the standard WPC cannot be fully corrected by simply replacing the trade price by the quote midpoint. Secondly, trade aggressiveness helps to explain the bias. The downward bias of small-size trades only affects to non-aggressive trades $(-49.1 \%)$ - the WPC of aggressive small-size trades is actually upward biased (11\%).

We conduct a number of robustness tests. We start by showing that the magnitude of the WPC friction-related bias depends on the time resolution of the analysis. In particular, the downward bias in the WPC of small size trades increases when computed over monthly rather than daily intervals. Quite the opposite, $\overline{\mathrm{WPC}}$ s computed at different frequencies and/or minimum daily return cutoffs converge. We also show that our results are not market-specific. For two representative samples of 1995 and 2005 NYSE-listed US common stocks, we corroborate the downward bias in the WPC of small-size trades. Yet, the estimated bias for US markets is of smaller magnitude than for the SSE. In days with positive returns and with consolidated (NYSE-NASDAQ-Pacific/Arca) trades and quotes, we document a $-12.35 \%$ bias in 1995 and a $-16.78 \%$ bias in 2005 . The friction-related bias decreases when we use NYSE trades and quotes only ( $-4.8 \%$ in 1995 and $-12.83 \%$ in 2005$)$.

Overall, we show that the WPC approach can be seriously biased by the presence of the friction-related component in the time series of the trade price change. In contrast, the $\overline{\mathrm{WPC}}$ approach provides accurate and reliable estimates.

The rest of the paper proceeds as follows. In Section 2, we summarize the stealth trading literature. In Section 3, we review the WPC approach. In Section 4, we describe the SSE database. In Section 5, we present $\overline{W P C}$ approach. In Section 6, we report our main findings. In Section 7, we provide robustness tests. In Section 8, we conclude.

\section{Strategic fragmentation of orders}

Studies about US markets during the 1980s and 1990s, spearheaded by BW93 seminal work, support the STH. With a sample of tender-offer target firms, BW93 find that $99 \%$ of the cumulative price change during the pre-announcement period occurs on medium sizes. Chakravarty (2001) uses TORQ data to show that nearly $80 \%$ of the cumulative price change is due to medium-size trades by institutional investors. Chakravarty, Chiyachantana, and Jiang (2008) report a disproportionately large WPC for mid-size trades in the 2-day interval immediately after (before) positive (negative) earnings surprises in the 1990s. Furthermore, institutional trading increases in the exact same intervals dominated by stealth traders.

More recently, price discovery in US markets has apparently shifted away from medium sizes and into small sizes. Using NASDAQ data, Choe and Hansch (2005) find support to the STH from 1993 to 1998, but from 1999 to 2003 about 70-85\% of the cumulative price change is due to small trades. They attribute this reversal to microstructure changes. ${ }^{6}$ Chakravarty, Van Ness, and Van Ness (2005) show that, after NYSE decimalization in 2001, the dollar adverse selection costs for medium-size trades decreased, which is compatible with informed traders shifting to smaller sizes. Using 2005 data from NASDAQ, Blau, Van Ness, and Van Ness (2009b) show that small short sales drive the short sales' predictability of negative next-day returns. Finally, O'Hara, Yao, and Ye (2014) use 2008-2009 NASDAQ data to show that more than $80 \%$ of the cumulative price change is accounted for trades of 100 -shares or less. They point to the raise of high frequency trading as the most likely explanation. The 2000s evidence for US markets suggests

\footnotetext{
${ }^{5}$ Here and in the rest of the text we use an overscore to indicate that a measure is friction-free.

${ }^{6}$ Higher transparence, lower tick sizes, and enhanced competition have reduced transaction costs, most notably for small-size orders (e.g., Chung, Chuwonganant, \& McCormick, 2004; Smith, 1998).
} 
that, alongside technological innovations and reductions in latency, the lower bound of trade size for stealth trading has decreased over time.

All the studies above use BW93's WPC approach described next.

\section{The WPC approach}

Suppose we have $K$ size categories of trades and $S$ stocks. For each stock $s=\{1, \ldots, S\}$ there are $N^{s}$ trades on a given time interval $t$. The price contribution of the size category $k$ for stock $s$ on the interval $t$ is given by

$$
P C_{k, t}^{S}=\frac{\sum_{n=1}^{N^{S}} \Delta p_{n} \delta_{n, k}}{\sum_{n=1}^{N^{S}} \Delta p_{n}},
$$

where $\Delta p_{n}=p_{n}-p_{n-1}$ is the difference between the price of trade $n$ and the price of trade $n-1$, and $\delta_{n, k}$ equals one if the $n$-th trade belongs to the size category $k$ and zero otherwise.

Let $\Delta p_{t}^{s}$ be the cumulative price change for stock $s$ on interval $t$, the denominator of Eq. (1). The weighted cross-sectional average price contribution for the size category $k$ on the interval $t$ is computed as ${ }^{8}$

$$
W P C_{k, t}=\sum_{s=1}^{S} w_{t}^{s} P C_{k, t}^{s}
$$

and the weights in Eq. (2) are given by

$$
w_{t}^{s}=\frac{\left|\Delta p_{t}^{s}\right|}{\sum_{s=1}^{s}\left|\Delta p_{t}^{s}\right|} .
$$

In prior studies, $\Delta p_{n}$ in Eq. (1) is defined either as the difference in prices (e.g., BW93) or as the log return (e.g., Chakravarty et al., 2005), and the length of $t$ varies from several months (e.g., Ascioglu, Comerton-Forde, \& McInish, 2011) to a few hours (e.g., Blau, Van Ness, \& Van Ness, 2009a). Some studies choose stocks with $\Delta p_{t}^{s}>0$ (e.g., Chakravarty, 2001), while some others ignore the sign of $\Delta p_{t}^{s}$ (e.g., O'Hara et al., 2014). Finally, overnight returns can be included (e.g., Chakravarty, 2001) or excluded (e.g., Choe \& Hansch, 2005). All studies, however, coincide in the way they define the price concession in Eq. (1), the WPC in Eq. (2), and the weights in Eq. (3).

BW93 propose two alternatives to the STH. The public information hypothesis (PIH) claims that price changes are entirely due to public information. Accordingly, the price contribution in Eq. (1) for each trade size category must be proportional to its share on total trades. The trading volume hypothesis (TVH) claims that large trades move prices more than small trades. Accordingly, the price contribution in Eq. (1) for each trade-size category must be proportional to its share on total volume. BW93 propose testing the STH against the PIH using the following pooled weighted-least-squares regression

$$
P C_{k, t}^{S}=\alpha_{S} D_{S, t}^{S}+\alpha_{M} D_{M, t}^{S}+\alpha_{L} D_{L, t}^{S}+\beta P T_{k, t}^{S}+\varepsilon_{k, t}^{s}
$$

where $D_{S, t}^{S}, D_{M, t}^{S}$ and $D_{L, t}^{S}$ are dummies that equal 1 when $P C_{k, t}^{s}$ falls into the small-, medium- or large-size category, respectively. $P T_{k, t}^{s}$ is the proportion of trades in size category $k$ for stock $s$ on the interval $t$. To test the STH against the TVH, we replace PT $T_{k, t}^{s}$ in Eq. (4) by the proportion of volume in size category $k$ for stock $s$ on the interval $t\left(P V_{k, t}^{s}\right)$. Regression weights are given by Eq. (3). Under the PIH or the TVH, the three $\alpha$ coefficients in Eq. (4) must be zero and $\beta$ must be one.

\section{The dataset}

We use trade and quote data from the SSE. ${ }^{9}$ Our database has several advantages over the most accessible database for US markets, the Monthly TAQ of the NYSE: all trades are reported, while the TAQ does not report odd lots (O'Hara et al., 2014); trades and best quotes are already matched within the same file, while TAQ users face an imprecise matching because of the treatment of millisecond time stamps (e.g., Holden \& Jacobsen, 2014); we do not need of inaccurate trade classification algorithms to determine the direction of trades (e.g., Chakrabarty, Pascual, \& Shkilko, 2014); we can accurately measure trade aggressiveness, and, finally, we avoid problems

\footnotetext{
7 There are a few studies about strategic fragmentation for non-US markets. Cai, Cai, and Keasey (2006) find stealth trading in the Chinese stock market. Ascioglu et al. (2011) show that small-size trades in the Tokyo Stock Exchange rule price formation except in high volatility days. Kalev and Pham (2009) find that in the Australian Stock Exchange stealth trading happens when liquidity is low. Menkhoff and Schmeling (2010) provide evidence of stealth trading on a foreign exchange electronic limit order market. Finally, Lin (2014) studies the relationship between transparency and the intensity of stealth trading practices on the Taiwan Stock Exchange. She shows that with greater pre-trade transparency, the WPC of small-size trades increased.

8 The weighting mitigates potential biases resulting from large cumulative price changes of volatile firms.

${ }^{9}$ In 2010, the World Federation of Exchanges ranked the SSE as the 5th largest stock exchange in Europe by market capitalization, and the 4th by total value of share trading.
} 
that could arise with market fragmentation (e.g., Holden \& Jacobsen, 2014) by using pre-MiFID (effective since November 1st, 2007) data. $^{10}$

We start with all the common stocks handled by the electronic order-driven platform of the SSE. Its continuous session spans from 9:00 a.m. to 5:30 p.m., preceded by a 30-minute opening call auction and followed by a 5-minute closing call auction. There are no designated market makers. Limit orders are stored in an open limit order book following the usual price-time priority rule. Every trade consumes liquidity either at the ask side or the bid side of the book. Price improvements are not possible. ${ }^{11}$

Our sample period extends from July 2000 to December 2006. During this period, the tick size was $0.01 €$, and there were no remarkable microstructure changes in the SSE. From the whole population of SSE-listed stocks, we keep 55 that, during the $61 / 2$ years considered, were IBEX-35 constituents for 1 year or more, never delisted from the electronic continuous platform, and traded for at least 3 consecutive years. ${ }^{12}$

Our database contains trade and best-quote data. For each trade, we know the price, size, the prevailing best quotes and displayed depth of the limit order book, and the time stamp (in seconds). While many trades may occur within the same second, the order of execution is known because of an internal sequence indicator. Together with trades, the database contains changes in the best quotes unrelated to trades. The quotes and depth prevailing right before and right after each trade are used to classify trades as aggressive or non-aggressive. We exclude data from the opening and closing call auctions, and from intraday rule-based 5-minute volatility auctions. $^{13}$

In Table 1, we provide descriptive sample statistics. We form four equally-sized portfolios based on market capitalization, whose composition is revised at the end of each year. The stocks in the upper quartile (" $\mathrm{C} 1$ ") are much more active and liquid than the other stocks in the sample.

\section{Methodological details: the friction-free WPC}

In our empirical application, we obtain daily WPCs for our sample of SSE-listed stocks. ${ }^{14}$ We define $p_{n}$ in Eqs. (2)-(3) as the marginal price of trade $n$, that is, the price of the last share transferred with the $n^{\text {th }}$ trade. We control for outliers in $P C_{k, t}^{s}$ in Eq. (1) by applying the rule of thumb (e.g., Hawkins, 1980) of dropping observations with a Z-score equal or larger than 3 in any trade-size category. ${ }^{15}$ We use the same trade-size cutoffs than in previous studies: 500 and 10,000 shares. In the SSE, there are not round lots as in US markets. Trades below 100 shares represent $14.75 \%$ of all trades in our sample. ${ }^{16}$

We obtain daily $\overline{\text { WPC }} \mathrm{s}$ as follows. Firstly, we use quote midpoints instead of prices to control for bid-ask bounce effects. The midpoint change is $\Delta q_{n}=q_{n}-q_{n-1}$, where $q_{n}$ stands for the average of the inside quotes right after trade $n .{ }^{17}$ Notice that a bid-askbounce-driven price change $\left(\Delta p_{n} \neq 0\right)$ results in a zero midpoint change $\left(\Delta q_{n}=0\right)$. We assume that $q_{n}$ can be decomposed into an efficient price $\left(m_{n}\right)$ and a transitory component $\left(s_{n}\right): q_{n}=m_{n}+s_{n}$ (e.g., Stoll, 2000). We define $m_{n}=E\left[\Im_{T} \mid \Phi_{n}\right]$ as the expected true value of the asset at some distant future conditional on the public information available right after trade $n$. The unexpected component of $\Delta q_{n}$ is $\Delta m_{n}=\Delta q_{n}-E\left[\Delta s_{n} \mid \Phi_{n-1}\right]$.

Secondly, we follow Hasbrouck (1991) in assuming that the relevant information in $\Phi_{n-1}$ is the history of mid-quote revisions and trades up to trade $n-1$. The trading process is summarized by the trade sign $\left(x_{n}\right)$, which equals 1 for buyer-initiated trades and -1 for seller-initiated trades; the signed trade size $\left(v_{n}\right)$ in shares, and the interaction of $\left\{x_{n}, v_{n}\right\}$ with the prevailing bid-ask spread $\left(s p_{n}\right)$ and the trade duration $\left(d_{n}\right)$ - time in seconds between consecutive trades. The rational for including trade durations builds upon Easley and O'Hara's (1992) model, in which trades of any size executed at short durations, have a higher average price impact. Dufour and Engle (2000) provide supporting evidence. The inclusion of the spread is justified by the adverse-selection costs literature. ${ }^{18}$ Empirically, Hasbrouck (1991) finds that trades that occur when the spread is wide have a relatively higher price impact. We assume that $E\left[\Delta s_{n} \mid \Phi_{n-1}\right]$ is a stable-over-time linear function of the history of trades and quotes, ${ }^{19}$

$$
\Delta q_{n}=\sum_{j=1}^{r}\left(\alpha_{j} \Delta q_{n-j}+\beta_{j}^{x} x_{n-j}+\beta_{j}^{v} v_{n-j}\right)+\sum_{j=1}^{r}\left(\beta_{j}^{x s p} x_{n-j} s p_{n-j}+\beta_{j}^{v s} v_{n-j} s p_{n-j}\right)++\sum_{j=1}^{r}\left(\beta_{j}^{x d} x_{n-j} d_{n-j}+\beta_{j}^{v d} v_{n-j} d_{n-j}\right)+\Delta m_{n}
$$

\footnotetext{
${ }^{10}$ Even nowadays, the fragmentation of the SSE is limited. In December 2013, the SSE accounts for 83.96\% of the trading volume on SSE-listed stocks, whilst Bat-ChiX has a $14.35 \%$ share and Turquoise a $1.59 \%$ share. Source: LiquidMetrix (http://www.if5.com/LiquidMetrix/Battlemap).

11 Iceberg orders are allowed, but not fully hidden orders (see Pardo \& Pascual, 2012).

12 The IBEX-35 is the official index. Regularly revised every semester, extraordinary revisions are also common. Index constituents represent $90.2 \%$ of the trading volume of the SSE within our sample period.

${ }^{13}$ For details on the short-lived rule-based trading halts of the SSE, see Abad and Pascual (2010).

14 In the robustness section, we report results with a monthly resolution.

15 With a cutoff of 1.5 , our results are the same.

${ }^{16}$ We have also considered stock-specific trade-size cutoffs derived from the empirical distribution of price changes of each particular stock in our sample. Our conclusions do not vary.

17 We also considered log prices and log quotes. Our findings and conclusions are the same.

${ }^{18}$ See Copeland and Galai (1983), Glosten and Milgrom (1985), Glosten (1994), and Handa, Schwartz, and Tiwari (2003), among others.

19 An anonymous referee proposes to include the limit order book (LOB) imbalance as an explanatory variable in Eq. (5). The LOB imbalance influences order choice (e.g., Biais, Hillion, \& Spatt, 1995; Ranaldo, 2004), and informs about posterior informational volatility (e.g., Foucault, Moinas, \& Theissen, 2007; Pascual \& Veredas, 2010). Using complementary data on the five best ask and bid levels of the SSE LOB, we find cross-sectional median correlations of roughly 0.99 between the stockmonth residuals of Eq. (5) with and without alternative LOB imbalance proxies. Our results would be unaltered by the inclusion of the LOB imbalance. Therefore, we proceed with the specification shown in Eq. (5).
} 
Table 1

Descriptive statistics.

This table contains descriptive statistics on our sample of 55 stocks traded in the SSE from July 2000 to December 2006 . Stocks are split into 4 portfolios based on the market capitalization at the beginning of each year. C1 are the largest stocks and C4 are the smallest stocks. In Panel A (B), we report the daily mean (median) and standard deviation (interquartile range) - in parenthesis, for each variable across stocks. "Trades" is the number of trades completed; "Volume" is the total amount transacted in million Euros; "Trade size" is the median trade size in shares; "price" is the average trade price; "Realized volatility" is the standard deviation of the 1-minute trade price changes; "Relative spread" is the bid-ask spread divided by the quote midpoint multiplied by 100; "Depth" is the number of shares displayed at the best ask and bid quotes in millions of Euros, and "Trade duration" is the time in seconds between consecutive trades.

\begin{tabular}{|c|c|c|c|c|c|c|c|c|}
\hline & & Volume & Trade size & & Realized & Relative & Depth & Trade \\
\hline & Trades & (millions $€$ ) & (shares) & Price & volatility & spread & (millios $€)$ & duration \\
\hline \multicolumn{9}{|c|}{ Panel A: Means and standard deviations } \\
\hline Sample & $\begin{array}{l}726.98 \\
(1067.59)\end{array}$ & $\begin{array}{l}31.358 \\
(79.81)\end{array}$ & $\begin{array}{l}1982.98 \\
(2584.40)\end{array}$ & $\begin{array}{l}19.00 \\
(14.68)\end{array}$ & $\begin{array}{l}0.0174 \\
(0.011)\end{array}$ & $\begin{array}{l}0.2529 \\
(0.245)\end{array}$ & $\begin{array}{l}0.2976 \\
(1.60)\end{array}$ & $\begin{array}{l}150.45 \\
(320.89)\end{array}$ \\
\hline $\mathrm{C} 1$ & $\begin{array}{l}1630.00 \\
(1615.14)\end{array}$ & $\begin{array}{l}96.375 \\
(135.04)\end{array}$ & $\begin{array}{l}3026.14 \\
(3109.24)\end{array}$ & $\begin{array}{l}17.76 \\
(9.21)\end{array}$ & $\begin{array}{l}0.0167 \\
(0.009)\end{array}$ & $\begin{array}{l}0.1596 \\
(0.185)\end{array}$ & $\begin{array}{l}0.5026 \\
(1.01)\end{array}$ & $\begin{array}{l}122.61 \\
(437.69)\end{array}$ \\
\hline $\mathrm{C} 2$ & $\begin{array}{l}503.02 \\
(605.90)\end{array}$ & $\begin{array}{l}12.413 \\
(15.83)\end{array}$ & $\begin{array}{l}1261.88 \\
(1154.25)\end{array}$ & $\begin{array}{l}26.26 \\
(21.52)\end{array}$ & $\begin{array}{l}0.0158 \\
(0.009)\end{array}$ & $\begin{array}{l}0.1998 \\
(0.109)\end{array}$ & $\begin{array}{l}0.1989 \\
(1.32)\end{array}$ & $\begin{array}{l}98.75 \\
(119.86)\end{array}$ \\
\hline $\mathrm{C} 3$ & $\begin{array}{l}433.69 \\
(456.60)\end{array}$ & $\begin{array}{l}8.080 \\
(10.02)\end{array}$ & $\begin{array}{l}1355.70 \\
(1723.86)\end{array}$ & $\begin{array}{l}20.03 \\
(13.04)\end{array}$ & $\begin{array}{l}0.0183 \\
(0.011)\end{array}$ & $\begin{array}{l}0.2950 \\
(0.331)\end{array}$ & $\begin{array}{l}0.1215 \\
(0.68)\end{array}$ & $\begin{array}{l}149.05 \\
(322.96)\end{array}$ \\
\hline $\mathrm{C} 4$ & $\begin{array}{l}283.24 \\
(327.14)\end{array}$ & $\begin{array}{l}4.282 \\
(5.93)\end{array}$ & $\begin{array}{l}2230.42 \\
(3257.92)\end{array}$ & $\begin{array}{l}12.30 \\
(9.29)\end{array}$ & $\begin{array}{l}0.0193 \\
(0.013)\end{array}$ & $\begin{array}{l}0.3694 \\
(0.246)\end{array}$ & $\begin{array}{l}0.3644 \\
(2.69)\end{array}$ & $\begin{array}{l}237.10 \\
(296.47)\end{array}$ \\
\hline \multicolumn{9}{|c|}{ Panel B: Medians and interquartile ranges } \\
\hline Sample & $\begin{array}{l}408 \\
(508)\end{array}$ & $\begin{array}{l}7.130 \\
(15.97)\end{array}$ & $\begin{array}{l}1247.40 \\
(1416.36)\end{array}$ & $\begin{array}{l}15.02 \\
(13.49)\end{array}$ & $\begin{array}{l}0.0147 \\
(0.011)\end{array}$ & $\begin{array}{l}0.1830 \\
(0.183)\end{array}$ & $\begin{array}{l}0.0740 \\
(0.095)\end{array}$ & $\begin{array}{l}74.67 \\
(89.53)\end{array}$ \\
\hline $\mathrm{C} 1$ & $\begin{array}{l}1123 \\
(1698)\end{array}$ & $\begin{array}{l}42.332 \\
(111.85)\end{array}$ & $\begin{array}{l}2122.05 \\
(2872.70)\end{array}$ & $\begin{array}{l}14.93 \\
(9.43)\end{array}$ & $\begin{array}{l}0.0147 \\
(0.010)\end{array}$ & $\begin{array}{l}0.1127 \\
(0.073)\end{array}$ & $\begin{array}{l}0.1633 \\
(0.258)\end{array}$ & $\begin{array}{l}27.15 \\
(39.08)\end{array}$ \\
\hline $\mathrm{C} 2$ & $\begin{array}{l}411 \\
(348)\end{array}$ & $\begin{array}{l}8.376 \\
(10.72)\end{array}$ & $\begin{array}{l}996.84 \\
(1044.97)\end{array}$ & $\begin{array}{l}19.54 \\
(23.58)\end{array}$ & $\begin{array}{l}0.0135 \\
(0.009)\end{array}$ & $\begin{array}{l}0.1705 \\
(0.124)\end{array}$ & $\begin{array}{l}0.0745 \\
(0.066)\end{array}$ & $\begin{array}{l}74.04 \\
(61.71)\end{array}$ \\
\hline $\mathrm{C} 3$ & $\begin{array}{l}350 \\
(305)\end{array}$ & $\begin{array}{l}5.338 \\
(7.31)\end{array}$ & $\begin{array}{l}943.55 \\
(956.83)\end{array}$ & $\begin{array}{l}16.28 \\
(16.67)\end{array}$ & $\begin{array}{l}0.0154 \\
(0.012)\end{array}$ & $\begin{array}{l}0.2194 \\
(0.196)\end{array}$ & $\begin{array}{l}0.0554 \\
(0.059)\end{array}$ & $\begin{array}{l}86.84 \\
(76.09)\end{array}$ \\
\hline $\mathrm{C} 4$ & $\begin{array}{l}224 \\
(264)\end{array}$ & $\begin{array}{l}2.548 \\
(4.04)\end{array}$ & $\begin{array}{l}1293.65 \\
(1347.93)\end{array}$ & $\begin{array}{l}10.53 \\
(9.93)\end{array}$ & $\begin{array}{l}0.0156 \\
(0.014)\end{array}$ & $\begin{array}{l}0.2981 \\
(0.255)\end{array}$ & $\begin{array}{l}0.0479 \\
(0.052)\end{array}$ & $\begin{array}{l}135.72 \\
(193.08)\end{array}$ \\
\hline
\end{tabular}

For each stock-month, we estimate Eq. (5) by OLS with White-robust standard errors. We discard the first $r$ trades each day, so that no lag reaches back to the previous day. We consider different options for $r$, from 5 to 15 lags. Our conclusions are robust to the choice of $r$, but the average first order autocorrelation of $\Delta m_{n}$ decreases up to $r=10$. So, we report findings exclusively for $r=10$. The average Durbin Watson statistic for $\Delta m_{n}$ across stock-monthly estimates is 1.99 (std. 0.0217).

We compute the WPC of a given trade-size category using of Eqs. (1) to (3), but replacing $\Delta p_{n}$ by the estimated $\Delta m_{n}$.

\section{Empirical findings}

\subsection{The friction-related bias}

In Table 2, we present the average WPC in Eq. (2) and its friction-free version ( $\overline{\mathrm{WPC}})$, computed using the time series of $\Delta m_{n}$ in Eq. (5). We also report the weighted average daily proportion of trades (\%T) and volume (\%V) using the weights in Eq. (3).

According to the WPC, medium-size trades account for more than 83\% of the price discovery in the SSE between 2000 and 2006, overcoming their \% (about 39\%) and \% (about 61\%). Large-size trades' contribution is about 18.5\%, largely above their \% ( $2.2 \%$ ) but below its \%V (23.4\%). In contrast, the WPC of small-size trades is negative ( $-1.6 \%)$, far below their \% $(58.7 \%)$ and \%V (15.7\%). Overall, the SSE displays similar stealth trading patterns than the US markets during the 1980s and 1990s.

Table 2

WPC friction-related bias

This table reports the daily average weighted price contribution (WPC), the daily average friction-free weighted price contribution ( $\overline{\mathrm{WPC}})$, the proportion of trades (\%T), and the proportion of volume in shares (\%V) for small-, medium-, and large-size trades in our sample. WPC is computed using trade price changes $(\Delta p)$, while WPC is computed using the unexpected quote midpoint changes $(\Delta m)$, estimated by the residuals of the time series model in Eq. (5), with $r=10$. We consider BW93 tradesize classification: (0 499] small-sized, [500 9,999) medium-size, [10,000 $\infty$ ) large-sized. $R$ is the daily (open-to-close) log return.

\begin{tabular}{|c|c|c|c|c|c|}
\hline Sample & Size category & WPC & $\overline{\mathrm{WPC}}$ & $\% \mathrm{~T}$ & $\% \mathrm{~V}$ \\
\hline \multirow[t]{3}{*}{ All days } & (0 499] & -1.63 & 37.09 & 58.71 & 15.74 \\
\hline & [500 9,999] & 83.17 & 55.43 & 39.11 & 61.02 \\
\hline & {$[10,000 \infty)$} & 18.46 & 7.48 & 2.19 & 23.24 \\
\hline \multirow[t]{3}{*}{$\mathrm{R}>1 \%$} & (0 499] & -39.79 & 32.92 & 57.29 & 14.20 \\
\hline & {$[500$ 9,999] } & 113.88 & 57.10 & 40.32 & 60.85 \\
\hline & {$[10,000 \infty)$} & 25.91 & 9.98 & 2.39 & 24.95 \\
\hline
\end{tabular}


The $\overline{\text { WPC }}$ approach shows a markedly different scenario. While medium-size trades account for a more modest $55.4 \%$ of the cumulative price change, the $\overline{\mathrm{WPC}}$ of small-size trades achieves a remarkable $37.1 \%$. In other words, we report a $38.71 \%$ friction-related downward bias in the daily WPC of SSE small-size trades between 2000 and 2006. While still below their \%T, the WPC of small-size trades is more than twice their \% V.

Chakravarty (2001) argues that, because of short-selling restrictions, informed sales in declining stocks are less likely than informed purchases in rising stocks. Hence, the chances of detecting stealth trading should increase if we pick days that display a significant price increase. In Table 2, we provide separated results for days with open-to-close $\log$ returns $(R)>1 \%$. With this subset of days, the friction-related downward bias in the WPC of small-size trades increases to $-72.7 \%$. The friction-related bias in WPC is therefore more prominent in periods of significant price discovery, precisely when information-motivated trading is more likely.

Table 2 reports negative WPC for small-size trades, a frequent finding in the literature. ${ }^{20}$ Some studies (e.g., Choe \& Hansch, 2005) associate negative WPCs with underperformance by retail traders (e.g., Barber \& Odean, 2000). Noticeably, our findings attribute negative WPCs to noise in the time series of price changes. By construction, only trades that generate non-zero $\Delta p_{n}$ contribute to the WPC. A negative WPC therefore implies that trades are pushing prices systematically in the "wrong" direction. We label a trade as being "wrong" if it causes a positive (negative) price change whilst the daily cumulative price change is negative (positive). Under the performance-based explanation, we should expect the initiators of small-size trades to be systematically wrong. In our sample, there are $11,337,755$ wrong trades, representing $21.5 \%$ of all trades. Nearly $46 \%$ of them are small-sized and $47 \%$ are medium-sized. Moreover, $22.1 \%$ of the small-sized trades are wrong, rather close to the $21.2 \%$ (19.8\%) of medium- (large-) size trades. It seems unlikely that these tiny differences could explain neither the negative WPC of small-size trades, nor the huge gap in WPC found between small- and medium-size trades. We therefore conclude that our results do not support a performance-based explanation for negative WPCs.

We follow a pooled regression approach to provide evidence on the statistical significance of the friction-related bias in WPC. The magnitude of the bias for a particular stock $i$, at day $d$, and trade-size category $s$ is computed as Bias $s_{i d s}=P C_{i d s}-\overline{P C}_{i d s}$, where $P C_{i d s}$ is the price contribution in Eq. (1), and $\overline{P C}_{i d s}$ is its friction-free version, obtained using $\Delta m_{t}$ and Eq. (5). We study both the direction (signed) bias and the magnitude (absolute) bias. Our stock-daily pooled regression model is of the following form:

$$
\text { Bias }_{i d s}=\alpha+\beta_{1} M_{i d s}+\beta_{2} L_{i d s}+\beta_{3} L C a p s_{i d s}+\varepsilon_{i d s}
$$

where $M_{\mathrm{ids}}\left(L_{\mathrm{ids}}\right)$ is a dummy variable that equals 1 if the trade-size category is medium (large). Thus, the intercept captures the effect of the omitted category: small-size trades. As control variable we include the dummy $L C a p_{\text {ids }}$ that equals 1 if stock $i$ 's market capitalization at the beginning of the corresponding year is above the upper quartile across stocks. We estimate Eq. (6) by weighted LS with Thompson (2011) double clustered standard errors. ${ }^{21}$ Weights are given by Eq. (3). We consider days with $R>1 \%$ only. We report the estimated coefficients in Table 3, with Thompson (2011) standard errors in parenthesis.

The intercept of the (signed) bias regression, which captures the average daily bias for small-size trades, is significantly negative at the $1 \%$ level. Hence, we confirm the statistical significance of the downward bias of small size trades reported in Table 2 . The coefficients for $M_{\mathrm{ids}}$ and $L_{\mathrm{ids}}$ are positive and larger than the intercept, confirming the upward-bias in the contributions of medium- and large-size trades. According to the absolute bias regression, the daily average magnitude of the bias is larger for small-size trades than for the other trade-size categories.

How much of the friction-related bias in WPC is due to bid-ask bounce? We address this question by estimating the cross-sectional average $W_{P C} C_{k, t}$ in Eq. (2) using quote midpoint changes $\left(\Delta q_{n}\right)$ instead of trade price changes $\left(\Delta p_{n}\right)$. Computed in this manner, the WPC accounts for bid-ask bounce, but ignores serial correlation in $\Delta q_{n}$. Table 4 reports the resulting decomposition.

The bid-ask bounce effect explains $85.3 \%$ of the bias across trade-size categories ( $89.6 \%$ for days with open-to-close returns $>1 \%$ ). Hence, replacing trade prices by quote midpoints in any empirical analysis should correct most of the bias, but still, $\overline{\text { WPC }}$ will provide more accurate estimates since transitory dynamics in $\Delta q_{n}$ markedly add to the bias.

Overall, the $\overline{\text { WPC }}$ approach provides empirical support to the simulation-based conclusion of van Bommel (2011), but using high frequency data: trading frictions can severely bias the WPC approach.

\subsection{Trade aggressiveness and the WPC friction-related bias}

Size-based classifications of trades, like those employed in stealth trading analyses, ignore order aggressiveness. Aggressive buy (sell) orders walk up (down) the book. Non-aggressive trades do not consume all the depth available at the best opposite quote. Consequently, aggressive trades of any given size carry on higher price concessions than non-aggressive trades of similar size. For example, suppose that the best and second best ask quotes are €23.45 and €23.47, respectively, and the best bid quote is €23.43; the available depth at each quote is 1,000 shares, and the previous trade $(n-1)$ was a buy at the current best ask quote. The marginal price $p_{n}$ of a medium-size market buy order of 1,100 shares would be $€ 23.47$, implying $\Delta p_{n}=€ 0.02$ and $\Delta q_{n}=€ 0.01$. In contrast, for a medium-size market buy order of 999 shares, $\Delta p_{n}=\Delta q_{n}=€ 0$. Consequently, the ex-post aggressive trade contributes to the

\footnotetext{
20 See Barclay and Warner (1993), Table 1), Chakravarty (2001), Table 1), Choe and Hansch (2005), Table 1), Chakravarty et al. (2008), Table 3), Ascioglu et al. (2011), Table 1).

21 Thompson (2011) standard errors cluster for both stock and time. The covariance estimator equals the estimator that clusters by stock plus the estimator that clusters by time minus the usual White (1980) robust estimator.
} 
Table 3

Friction-related bias: Regression analysis.

This table reports the estimated coefficients of pooled weighted least square regressions with Thompson (2011) standard errors (in parenthesis) that cluster by both firm and time (day). We use two alternative dependent variables: (a) the friction-related bias in the daily price contribution ( $P C$ ), and (b) the absolute value of that bias. We use three trade-size categories: (0 499] small-sized, [500 9,999] medium-sized, and [10,000 $\infty$ ) large-sized. For stock $(i)$, day $(d)$, and trade size category $(s)$, we compute $P C_{\text {ids }}$ as the sum of the trade price changes divided by the daily cumulative price change. The friction-related bias is the difference between $P C_{\text {ids }}$ and the friction-free $P C_{\text {ids }}$. The latter is obtained using the unexpected quote midpoint changes given by the residuals of the time series model in Eq. (5) $(r=10)$. We only consider days with open-to-close returns larger than $1 \%$. Weights are given by Eq. (3). The regression variables $M$ and $L$ are dummies for medium-sized and large-sized trades, respectively. The omitted category is small-size trades. The dummy LCaps equals 1 when the observation corresponds to a large cap in our sample. Large caps are defined as the stocks in the upper quartile in terms of yearly average market capitalization. Large caps constituents are revised yearly.

\begin{tabular}{|c|c|c|}
\hline Coeff. & Bias & |Bias $\mid$ \\
\hline$M$ & $\begin{array}{l}0.0934^{* *} \\
(6.57)\end{array}$ & $\begin{array}{l}-0.0254^{* *} \\
(-6.50)\end{array}$ \\
\hline$L$ & $\begin{array}{l}0.0660^{* *} \\
(5.77)\end{array}$ & $\begin{array}{l}-0.1005^{* *} \\
(-16.12)\end{array}$ \\
\hline LCaps & $\begin{array}{l}0.0003 \\
(0.25)\end{array}$ & $\begin{array}{l}0.0487^{* *} \\
3.198\end{array}$ \\
\hline Intercept & $\begin{array}{l}-0.0518^{* *} \\
(-6.52)\end{array}$ & $\begin{array}{l}0.1319^{* *} \\
(12.65)\end{array}$ \\
\hline Obs. & 85740 & \\
\hline Adj. $R^{2}$ & 0.045 & 0.086 \\
\hline
\end{tabular}

*(**) means stistically significant at the $0.05(0.01)$.

Table 4

Sources of bias: bid-ask bounce vs. serial correlation.

This table decomposes the WPC friction-related bias into two orthogonal components: a bid-ask bounce driven component and a bid-ask-bounce-free serial correlation driven component. We use BW93's trade-size classification: (0 499] small-sized, [500 9,999] medium-size, [10,000 $\infty$ ) large-sized. $R$ is the daily (open-to-close) log return.

\begin{tabular}{|c|c|c|c|c|}
\hline \multirow[t]{2}{*}{ Days } & \multirow[b]{2}{*}{ Trade-size category } & \multirow[b]{2}{*}{ Bias } & \multicolumn{2}{|c|}{ Bias decomposition } \\
\hline & & & $\begin{array}{l}\text { Bid-ask } \\
\text { bounce }\end{array}$ & $\begin{array}{l}\text { Serial } \\
\text { correlation }\end{array}$ \\
\hline \multirow[t]{4}{*}{ All } & (0 499] & -38.71 & 0.856 & 0.144 \\
\hline & [500 9999] & 27.73 & 0.862 & 0.138 \\
\hline & {$[10000 \infty)$} & 10.98 & 0.842 & 0.158 \\
\hline & & mean & 0.853 & 0.147 \\
\hline \multirow[t]{4}{*}{$\mathrm{R}>1 \%$} & (0 499] & -72.71 & 0.892 & 0.108 \\
\hline & [500 9999] & 56.78 & 0.888 & 0.112 \\
\hline & {$[10000 \infty)$} & 15.93 & 0.908 & 0.092 \\
\hline & & mean & 0.896 & 0.104 \\
\hline
\end{tabular}

WPC, whereas the ex-post non-aggressive trade does not. This simple example illustrates why, in order-driven markets, the relative (to the available depth) trade size matters in computing the WPC.

Continuing with the above example, we illustrate now that, for any given trade size category, non-aggressive trades are more likely to lead to pure noise-related contributions than similar aggressive trades. Let trade $n-1$ be now a sell at the current bid quote $\left(p_{n-1}=€ 23.43\right)$ rather than a buy. In this case, the 1,100- and 999-share trades both contribute to the WPC: $\Delta p_{n}=€ 0.04$ and $€ 0.02$, respectively. Whilst the aggressive trade contribution is partly informative $\left(\Delta q_{n}=€ 0.01\right)$, the non-aggressive trade contribution is pure noise $\left(\Delta q_{n}=€ 0\right)$.

In this section, we question if trade aggressiveness can explain, at least in part, the downward friction-related bias in the WPC of small-size trades. In Table 5 - Panel A, we provide statistics on trade aggressiveness. In our sample, non-aggressive trades outnumber aggressive trades by more than 3.5 to 1 . Notably, non-aggressive trades are far more common among small-size trades (82.8\%) than among any other trade size category.

In Table 5 - Panel B, we use pooled regressions to study the distinct role that aggressive and non-aggressive trades play on the WPC statistic. For each stock $i$, day $d$, and trade-size category $s$, we compute the proportion of both aggressive and non-aggressive trades that: (a) contribute to the WPC $\left(\Delta p_{n} \neq 0\right)$; (b) contribute but with a noise-driven price change $\left(\Delta p_{n} \neq 0\right.$ and $\left.\Delta q_{n}=0\right)$; (c) are wrong, and (d) satisfy both (b) and (c). ${ }^{22}$ Our pooled regression model is

$$
y_{i d s a}=\alpha+\beta_{1} M_{i d s a}+\beta_{2} L_{i d s a}+\beta_{3} A S_{i d s a}+\beta_{4} A M_{i d s a}+\beta_{5} A L_{i d s a}+\beta_{6} L C a p s_{i d s a}+\varepsilon_{i d s a}
$$

where sub-index $a$ represents the aggressiveness category (i.e., aggressive v. non-aggressive). The dependent variable $y$ is one of the (a) to (d) daily proportions defined above; $M, L, A S, A M$, and $A L$ are all dummy variables: $M(L)$ equals 1 if trades are medium- (large-)

\footnotetext{
${ }^{22}$ Wrong trades are defined as in the prior subsections.
} 
Table 5

Trade aggressiveness and trading frictions.

In Panel A, we provide general statistics about the distribution of aggressive and non-aggressive trades among trade-size categories. An aggressive trade walks up or down the book. A non-aggressive trade does not consume all the available depth at the opposite side of the market. In Panel B, we report pooled regression in Eq. (7) on the stock-daily-trade-size proportion of aggressive and non-aggressive trades that: [a] contribute to the WPC; [b] contribute to the WPC but with bid-ask bounce driven price change; [c] are wrong trades, and [d] are wrong trades that contribute with a bid-ask bounce driven price change. A trade is wrong if it causes a positive (negative) price change whilst the daily cumulative price change, the denominator in Eq. (1), is negative (positive). Thompson (2011) standard errors are reported in parenthesis. We use BW93's trade-size classification: ( 0 499] small-sized, [500 9,999] medium-size, [10,000 $\infty$ ) large-sized. The regression variables $M$ and $L$ are dummies for medium-size and large-size non-aggressive trades, respectively. $A S, A M$ and $A L$ are dummies for small-size, medium-size and large-size aggressive trades, respectively. The omitted category is small-size non-aggressive trades. The dummy LCaps equals 1 when the observation corresponds to a large cap in our sample. Large caps are defined as the stocks in the upper quartile in terms of yearly average market capitalization. Large caps constituents are revised yearly.

\begin{tabular}{|c|c|c|c|c|}
\hline \multicolumn{5}{|c|}{ Panel A: Statistics on aggressiveness } \\
\hline & Small & Medium & Large & Total \\
\hline \multirow[t]{2}{*}{ Aggr. } & $3,347,577$ & $6,953,005$ & $1,299,606$ & $11,600,188$ \\
\hline & $17.20 \%$ & $35.03 \%$ & $56.83 \%$ & \\
\hline \multirow[t]{2}{*}{ Non-aggr. } & $20,289,541$ & $18,234,297$ & $2,581,269$ & $41,105,107$ \\
\hline & $82.80 \%$ & $64.97 \%$ & $43.17 \%$ & \\
\hline \multicolumn{5}{|c|}{ Panel B: Pooled regressions } \\
\hline \multirow[t]{2}{*}{ Coeff. } & [a] & {$[\mathrm{b}]$} & {$[c]$} & {$[\mathrm{d}]$} \\
\hline & $\begin{array}{l}\text { Contrib. } \\
\text { to WPC }\end{array}$ & $\begin{array}{l}\text { Bid-ask } \\
\text { bounce } \\
\text { driven }\end{array}$ & $\begin{array}{l}\text { Wrong } \\
\text { trades }\end{array}$ & $\begin{array}{l}\text { Wrong }+ \\
\text { bid-ask } \\
\text { bounce driv. }\end{array}$ \\
\hline \multirow[t]{2}{*}{$M$} & $-0.0296^{* *}$ & $-0.0091^{*}$ & $-0.0128^{* *}$ & -0.0126 \\
\hline & $(-7.94)$ & $(-2.58)$ & $(-13.96)$ & $(-6.58)$ \\
\hline \multirow[t]{2}{*}{$L$} & 0.0078 & $0.0494^{* *}$ & $-0.0244^{* *}$ & 0.0052 \\
\hline & $(1.11)$ & $(6.51)$ & $(-11.21)$ & $(1.25)$ \\
\hline \multirow[t]{2}{*}{ AS } & $0.0393^{* *}$ & $-0.2472^{* *}$ & $0.1320^{* *}$ & -0.1298 \\
\hline & $(3.48)$ & $(-27.06)$ & $(42.40)$ & $(-24.37)$ \\
\hline \multirow[t]{2}{*}{$A M$} & $0.1276^{* *}$ & $-0.2319^{* *}$ & $0.1559^{* *}$ & -0.1224 \\
\hline & $(9.03)$ & $(-22.52)$ & $(46.50)$ & $(-20.67)$ \\
\hline \multirow[t]{2}{*}{$A L$} & $0.2942^{* *}$ & $-0.1057^{* *}$ & $0.1615^{* *}$ & -0.0555 \\
\hline & $(14.08)$ & $(-4.82)$ & $(29.68)$ & $(-4.56)$ \\
\hline \multirow[t]{2}{*}{ LCaps } & $-0.0536^{*}$ & $-0.0063^{*}$ & -0.0184 & -0.0035 \\
\hline & $(-2.55)$ & $(-2.08)$ & $(-1.95)$ & $(-2.06)$ \\
\hline \multirow[t]{3}{*}{ Intercept } & $0.4558^{* *}$ & $0.2907^{* *}$ & $0.0832^{* *}$ & 0.1528 \\
\hline & $(51.30)$ & $(35.25)$ & $(17.44)$ & $(30.71)$ \\
\hline & & & Obs. & 389117 \\
\hline Adj. $\mathrm{R}^{2}$ & 0.239 & 0.337 & 0.238 & 0.175 \\
\hline
\end{tabular}

** (*) means statitsically signfiicant at the $1 \%(5 \%)$ level.

sized and non-aggressive; $A S, A M$ and $A L$ equal 1 if trades are aggressive and small-sized, medium-sized, and large-sized, respectively. Thus, the omitted category is small-size non-aggressive trades. We use the same control variable as in Eq. (6). Eq. (7) is estimated by weighted LS with Thompson (2011) standard errors.

Table 6

Trade aggressiveness and the WPC bias.

This table reports the daily average weighted price contribution (WPC), the daily average friction-free weighted price contribution ( $\overline{\text { WPC }})$, the friction related bias in WPC, the proportion of trades (\% ), and the proportion of volume in shares (\%) for small-, medium-, and large-size aggressive and non-aggressive trades in our sample. A trade is aggressive if it consumes at least the available depth (both displayed and non-displayed) at the best quote on the opposite side of the market. We consider BW93's trade-size classification: (0 499] small-sized, [500 9,999] medium-sized, [10,000 $\infty$ ) large-sized. $R$ is the daily (open-to-close) log return.

\begin{tabular}{|c|c|c|c|c|c|c|c|}
\hline Sample & Size category & Aggr. & WPC & $\overline{\mathrm{WPC}}$ & Bias & $\% \mathrm{~T}$ & $\% \mathrm{~V}$ \\
\hline \multirow[t]{6}{*}{ All days } & \multirow[t]{2}{*}{ (0 499] } & No & -27.72 & 21.37 & -49.09 & 44.95 & 10.57 \\
\hline & & Yes & 26.92 & 15.86 & 11.05 & 11.07 & 3.69 \\
\hline & \multirow[t]{2}{*}{ [500 9,999] } & No & 21.09 & 11.98 & 9.11 & 26.89 & 31.82 \\
\hline & & Yes & 61.68 & 43.27 & 18.42 & 13.96 & 26.76 \\
\hline & \multirow[t]{2}{*}{$10,000 \infty$} & No & 6.29 & 1.13 & 5.16 & 1.88 & 11.02 \\
\hline & & Yes & 11.73 & 6.39 & 5.35 & 1.24 & 16.15 \\
\hline \multirow[t]{6}{*}{$R>1 \%$} & \multirow[t]{2}{*}{ (0 499] } & No & -57.85 & 12.58 & -70.43 & 45.09 & 10.55 \\
\hline & & Yes & 32.08 & 22.70 & 9.38 & 11.86 & 4.12 \\
\hline & \multirow[t]{2}{*}{ [500 9,999] } & No & 36.48 & 5.70 & 30.77 & 25.55 & 31.06 \\
\hline & & Yes & 69.03 & 50.55 & 18.48 & 14.38 & 27.52 \\
\hline & \multirow[t]{2}{*}{$10,000 \infty$} & No & 7.19 & 0.64 & 6.55 & 1.81 & 10.41 \\
\hline & & Yes & 13.08 & 7.82 & 5.26 & 1.32 & 16.33 \\
\hline
\end{tabular}


Table 7

Friction-related bias: regression analysis.

This table reports the estimated coefficients of pooled weighted least square regressions with Thompson (2011) standard errors (in parenthesis). We use two alternative dependent variables: (a) the friction related bias in the daily price contribution $(P C)$, and (b) the absolute value of that bias. We use three trade-size categories: ( 0 499] small-sized, [500 9,999] medium-sized, and [10,000 $\infty$ ) large-sized. We also separate aggressive from non-aggressive trades in each trade-size category. An aggressive trade consumes at least the available depth (both displayed and non-displayed) at the best quote on the opposite side of the market. For each resulting trade sizeaggressiveness ( $s a$ ) category, for each stock $i$, and each day $d$, we compute $P C_{\text {idsa }}$ as the sum of the trade price changes divided by the daily cumulative price change. The friction related bias is the difference between $P C_{\text {idsa }}$ and the friction-free $P C_{\text {idsa. }}$. The latter is obtained using the unexpected quote midpoint changes given by the residuals of the time series model in Eq. (5) $(r=10)$. We only consider days with open-to-close returns larger than $1 \%$. Weights are given by Eq. ( 3 ). The regression variables $A S, M, A M, L, A L$ are dummies for the following categories of trades: small-sized and aggressive, medium-sized and non-aggressive, medium-sized and aggressive, largesized and non-aggressive, and large-sized and aggressive, respectively. The omitted category is small-size non-aggressive trades. LCaps equals 1 when the observation corresponds to a large cap in our sample. Large caps are defined as the stocks in the upper quartile in terms of yearly average market capitalization. Large caps constituents are revised yearly.

\begin{tabular}{|c|c|c|}
\hline Coeff. & Bias & $\mid$ Bias $\mid$ \\
\hline AS & $\begin{array}{l}0.1323^{* *} \\
(4.44)\end{array}$ & $\begin{array}{l}-0.1199^{* *} \\
(-7.09)\end{array}$ \\
\hline$M$ & $\begin{array}{l}0.1534^{* *} \\
(4.99)\end{array}$ & $\begin{array}{l}-0.0887^{* *} \\
(-8.47)\end{array}$ \\
\hline$A M$ & $\begin{array}{l}0.1663^{* *} \\
(4.49)\end{array}$ & $\begin{array}{l}-0.0826^{* *} \\
(-6.678)\end{array}$ \\
\hline$L$ & $\begin{array}{l}0.1333^{* *} \\
(5.08)\end{array}$ & $\begin{array}{l}-0.1645^{* *} \\
(-13.82)\end{array}$ \\
\hline$A L$ & $\begin{array}{l}0.1317^{\text {** }} \\
(4.66)\end{array}$ & $\begin{array}{l}-0.1569 \text { ** } \\
(-12.59)\end{array}$ \\
\hline LCaps & $\begin{array}{l}0.0004 \\
(0.35)\end{array}$ & $\begin{array}{l}0.0509^{* *} \\
(3.21)\end{array}$ \\
\hline Intercept & $\begin{array}{l}-0.1180^{* *} \\
(-4.82)\end{array}$ & $\begin{array}{l}0.1750^{* *} \\
(13.73)\end{array}$ \\
\hline Obs. & 85740 & \\
\hline Adj. $R^{2}$ & 0.089 & 0.173 \\
\hline
\end{tabular}

$\left.*^{*}\right)$ means stistically significant at the $0.05(0.01)$.

In general, our findings corroborate that non-aggressive trades more often contribute to the WPC without enhancing price discovery. Always in relative terms to the total number of trades in each trade-size/aggressiveness category, non-aggressive trades of all sizes contribute less often to the WPC than aggressive trades (2nd column), but are more often associated with bid-ask bounce driven price changes ( $3 r d$ column). Initiators of aggressive trades are more often wrong (4th column) than initiators of non-aggressive trades but, even then, price changes are less likely due to bid-ask bounce (5th column). Finally, all the estimated models suggest that nonaggressive small-size trades tend to add noise to the WPC more often than non-aggressive medium-size trades.

We postulate that the prevalence of non-aggressive trades among small-size trades (Table 5 - Panel A) together with the higher propensity of non-aggressive trades to cause noise-driven price changes (Table 5 - Panel B) could partially explain the downward friction-related bias in the WPC of small-size trades. In Table 6, we report the WPC and WPC of our six trade-size/aggressiveness categories. We report results for all days and days with $R>1 \%$.

We find that the friction-related downward bias in the WPC of small-size trades concentrates on non-aggressive trades. The WPC of aggressive small-size trades is, in effect, upward biased. In days with $R>1 \%$, the downward bias of small-size non-aggressive trades rises to $-70.4 \%$, whilst non-aggressive medium-size trades experience the highest upward bias. In days with $R>1 \%$, small- and medium-size aggressive trades display $\overline{\mathrm{WPC}}$ s of $22.7 \%$ and $50.55 \%$, respectively, more than proportional to their \%T and \%V. Markedly, the $\overline{\mathrm{WPC}}$ of non-aggressive medium-size trades reveals that these trades do not use to conceal informed traders.

We use the pooled regression model in Eq. (7) to test the statistical significance of the friction-related bias in the WPC. As dependent variable $(y)$, we use now either the signed bias $\left(\right.$ Bias $\left._{i d s a}=P C_{i d s a}-\overline{P C}_{i d s a}\right)$ or the absolute bias per trade-size/aggressiveness category. We report the weighted LS estimates with Thompson (2011) standard errors in Table 7.

The intercept of the (signed) bias regression is significantly negative at the $1 \%$ level, whilst the coefficient for the other categories is positive and larger than the intercept. Therefore, we confirm a statistically significant downward bias in the WPC of small-size nonaggressive trades. Medium-size aggressive and non-aggressive trades report the highest significant upward biases. The |bias| regression confirms that the average magnitude of the bias is much larger for small-size non-aggressive trades than for the other categories.

\subsection{Trading frictions and formal tests of the STH}

Next, we use the WPC approach to provide evidence on the robustness of the BW93's methodology to test the STH. In Table 8 - Panel A, we report the estimated pooled weighted LS regression in Eq. (4) using either $P C_{i d s}$ or $\overline{P C}_{i d s}$ as the explanatory variable. ${ }^{23}$ We focus on stock-days with $R>1 \%$ to increase the likelihood of detecting stealth trading.

The public information (PIH) and the trading volume (TVH) hypotheses are rejected across the board. The nulls that the coefficient of $P T$ or $P V$ equals one and that all dummy variables have zero coefficients are rejected at the $1 \%$ level. Ignoring trading frictions, our

\footnotetext{
${ }^{23}$ As in previous regressions, we compute Thompson (2011) double clustered standard errors for the coefficient estimates. We omit them in this and posterior Tables for space limitations.
} 
Table 8

The friction-related bias and formal tests of the STH.

In Panel A, we report the estimated pooled weighted least square regression in Eq. (4) with Thompson (2011) standard errors (omitted). The dependent variable is either the price contribution $(P C)$ or the friction-free price contribution $(\overline{\mathrm{PC}})$ of the trade size category $k$, for stock $s$, and day $d$. We consider three trade size categories: (0 499] small-sized, [500 9,999] medium-size, [10,000 $\infty$ ) large-sized. The weights are given by Eq. (3). PIH stands for public information hypothesis and TVH for trading volume hypothesis. Under the PIH (TVH), the null hypothesis is that the three trade-size coefficients equal zero and the PT (PV) coefficient equals one. Wald tests are provided. $R$ is the daily cumulative price change. In Panel B, we expand Eq. (4) to consider six trade-size categories: aggressive and non-aggressive small-, medium-, and large-size trades. We focus on stock-days with open-to-close returns $(\mathrm{R})>1 \%$.

\begin{tabular}{|c|c|c|c|c|c|}
\hline \multirow[t]{2}{*}{ Coeff. } & & \multicolumn{2}{|l|}{$P C-R>1 \%$} & \multicolumn{2}{|l|}{$\overline{\mathrm{PC}}-R>1 \%$} \\
\hline & & $\mathrm{PIH}$ & TVH & $\mathrm{PIH}$ & TVH \\
\hline \multicolumn{6}{|c|}{ Panel A: Ignoring trade aggressiveness } \\
\hline $\mathrm{S}$ & & $-1.287^{* *}$ & $-0.522^{* *}$ & $-0.069^{* *}$ & $0.273^{* *}$ \\
\hline M & & $0.452^{* *}$ & $0.242^{* *}$ & $0.286^{* *}$ & $0.277^{* *}$ \\
\hline $\mathrm{L}$ & & $0.178^{* *}$ & $-0.118^{* *}$ & $0.064^{* *}$ & $-0.051^{* *}$ \\
\hline PT & & $1.656 \dagger$ & & $0.719 \dagger$ & \\
\hline PV & & & $1.395+$ & & $0.501 \dagger$ \\
\hline Adj. $\mathrm{R}^{2}$ & & 0.189 & 0.189 & 0.237 & 0.232 \\
\hline Obs. & & 44059 & 44059 & 43623 & 43623 \\
\hline \multicolumn{6}{|c|}{ Panel B: Controlling for trade aggressiveness } \\
\hline \multirow[t]{2}{*}{$\mathrm{S}$} & non-aggr. & $-0.861^{* *}$ & $-0.760^{* *}$ & $-0.169^{* *}$ & $0.073^{* *}$ \\
\hline & aggr. & $0.243^{*}$ & $0.252^{* *}$ & $0.147^{* *}$ & $0.208^{* *}$ \\
\hline \multirow[t]{2}{*}{ M } & non-aggr. & $0.250^{*}$ & -0.028 & $-0.101^{* *}$ & -0.074 \\
\hline & aggr. & $0.639 * *$ & $0.302^{* *}$ & $0.417^{* *}$ & $0.386^{* *}$ \\
\hline \multirow[t]{2}{*}{$\mathrm{L}$} & non-aggr. & $0.072^{* *}$ & $-0.024^{* *}$ & -0.005 & $-0.037^{* *}$ \\
\hline & aggr. & $0.131^{* *}$ & $-0.084^{* *}$ & $0.072^{* *}$ & 0.005 \\
\hline PT & & $0.539 \dagger \dagger$ & & $0.639+$ & \\
\hline PV & & & $1.353+\dagger$ & & $0.438 \dagger$ \\
\hline Adj. $\mathrm{R}^{2}$ & & 0.134 & 0.149 & 0.117 & 0.115 \\
\hline Obs. & & 88132 & 88132 & 87249 & 87249 \\
\hline
\end{tabular}

*, ** means statistically different from zero at the $5 \%(1 \%)$ level.

$\dagger(\dagger)$ means statistically different from one at the $5 \%$ (1\%) level (Wald test).

results suggest that informed traders concentrate on medium-size trades $\left(\alpha_{M}>0\right)$, whilst small-size trades play no role in price discovery $\left(\alpha_{S}<0\right)$. Without trading frictions, however, $\alpha_{S}$ becomes positive and significant in the TVH regression. In fact, the null $\alpha_{S}=\alpha_{M}$ cannot be rejected at the $1 \%$ level.

In Panel B of Table 8, we extend Eq. (4) to control for trade aggressiveness. Ignoring trading frictions, our regressions do reveal the significant role that small-size aggressive trades play in price discovery. However, the PIH regression assigns a comparable role to medium-size non-aggressive trades, which contradicts the WPC results in Table 6. Once we filter the price changes for trading frictions, our results in all regressions reveal disproportional contributions for only small- and medium-size aggressive trades.

Overall, our results cast some doubts on the robustness of the formal tests of the STH to trading frictions.

\section{Robustness}

\subsection{Monthly WPC}

Do our results depend on the time resolution of the WPC analysis? In Table 9, we present the average WPC across stocks and months, together with the estimated friction-related bias in WPC, and the weighted average daily proportion of trades (\%) and volume (\%). We focus on monthly observations with $R>2.5 \%$ to increase the likelihood of observing stealth trading. We also control for trade aggressiveness.

We find that the magnitude of the friction-related bias depends on the time resolution. Namely, the bias increases with time aggregation. As in the daily analysis, small-size aggressive trades' WPC is downward biased, whilst medium-size trades' WPC experiences the highest upward bias. Once we control for trading frictions, however, the resulting WPCs are close to those in Table 6 . Hence, the WPC approach provides not only more accurate estimates than the WPC approach, but also more robust and reliable.

\subsection{US markets}

Is the friction-related bias of the WPC a market-specific phenomenon? In this section, we test if it extends to US markets, where the stealth trading research has been more active.

Our US data analysis suffers from limitations inherent to the database we employ, the Monthly TAQ of the NYSE: (i) The TAQ database does not report odd lots. O'Hara et al. (2014) show that small-size odd lots remarkably contribute to price discovery. (ii) We cannot measure trade aggressiveness because the TAQ does not provide order-level data (e.g., Bacidore, Ross, \& Sofianos, 2003). 


\section{Table 9}

Monthly WPC.

For small-, medium-, and large-size aggressive and non-aggressive trades in our sample, this table reports the monthly average weighted price contribution (WPC); the monthly average friction-free weighted price contribution ( $\overline{\mathrm{WPC}})$; the friction related bias in WPC, the proportion of trades (\%T), and the proportion of volume in shares $(\% \mathrm{~V})$. A trade is aggressive if it consumes at least the available depth (both displayed and non-displayed) at the best quote on the opposite side of the market. We consider BW93's trade-size classification: ( 0499$]$ small-sized, [500 9,999] medium-sized, [10,000 $\infty$ ) large-sized. $R$ is the daily (open-to-close) log return. We report trades for stock-months with $R>2.5 \%$ to increase the likelihood of observing stealth trading.

\begin{tabular}{|c|c|c|c|c|c|c|}
\hline Sample & $\begin{array}{l}\text { Trade size } \\
\text { category }\end{array}$ & Aggr. & $\overline{\mathrm{WPC}}$ & Bias & $\% \mathrm{~T}$ & $\% \mathrm{~V}$ \\
\hline \multirow[t]{6}{*}{$R>2.5 \%$} & (0 499] & No & 30.03 & -358.55 & 43.69 & 7.84 \\
\hline & & Yes & 12.27 & 79.67 & 10.16 & 2.87 \\
\hline & [500 9,999] & No & 15.76 & 99.48 & 27.98 & 30.03 \\
\hline & & Yes & 35.23 & 137.31 & 13.98 & 24.38 \\
\hline & {$[10,000 \infty)$} & No & 1.71 & 20.96 & 2.59 & 14.71 \\
\hline & & Yes & 5.00 & 21.13 & 1.61 & 20.17 \\
\hline
\end{tabular}

(iii) The TAQ does not include a trade-initiator flag. Thus, we need to align trades and quotes to assess the direction of trades. This task is particularly problematic in modern high frequency markets. ${ }^{24}$ For all these reasons, our findings must be carefully interpreted.

We avoid dealing with high frequency markets using 1995 and 2005 data (whole years). By choosing these particular periods, we are also able to test if the friction-related bias in WPC is independent of the lower bound of trade size for stealth trading (e.g., Choe \& Hansch, 2005).

We form a representative sample of common stocks by market capitalization as follows. We start with the CRSP universe of common stocks $($ SHRCLS $=$. or $\mathrm{A}$ ) and restrict it to NYSE-listed stocks (PRIMEXCH $=\mathrm{N}$ ). We eliminate stocks with SIC code greater than 9000 (Government owned), between 8880 and 8888 (ADRs and foreign Governments), and between 4800 and 4999 (regulated utilities). We also drop stocks from non-US companies, with security status other than "regular" (SECSTAT $\neq \mathrm{R}$ ), with dual shares, with trade prices below $\$ 2$ or above $\$ 200$, or with no daily price or volume records.

We rank and divide the remaining assets in four groups by daily average market capitalization. We discard those in the bottom quartile (smallest stocks). For each of the top three groups, we retain the 200 largest stocks, sort them by ticker symbol, and then pick every 4th stock. This procedure results in 150 randomly selected stocks ( 50 for each size group) with a significant size difference between groups.

We use trades and quotes during regular market hours. We clean the trade and quote files with the filters in Hendershott and Moulton (2011, p. 578) and Chakrabarty and Moulton (2012, p. 14). To avoid problems of stale quotes, we construct two BBO series for each stock, one from NYSE quotes only (NYSE BBO) and the other with quotes from NYSE, Pacific Exchange/Arca and NASDAQ (NBBO). ${ }^{25}$

Regarding the alignment of trades and quotes, we make no allowance of trade reporting lags. ${ }^{26}$ NYSE BBO quotes are aligned with NYSE trades only. The BBO constructed from the N/P/T/Q quotes is aligned with trades originating from those exchanges. We use three alternative trade classification algorithms: the tick rule, Lee and Ready (1991), and Ellis, Michaely, and O'Hara (2000). ${ }^{27}$ Overall, our findings are robust to the classification rule.

In Table 10, we provide the WPC for our sample of 1995 (Panel A) and 2005 (Panel B) NYSE-listed stocks. Using the NBBO, the 1995 WPC of small-size trades is $11.54 \%$, whilst in 2005 raises to $60.23 \%{ }^{28}$ Using NYSE data only, the 1995 WPC of small-size trades is higher (19.18\%) but only slightly lower in 2005 (57.65\%). In days with strictly positive open-to-close returns, the 2005 WPC of small-size trades falls to $48.53 \%$ with NBBO and 36\% with NYSE BBO. Overall, results in Table 10 illustrate the increasing role of small-size trades in price discovery previously reported for US stock exchanges.

In Table 10, we also report the estimated friction-related bias (WPC- $\overline{\text { WPC }}$ ) using Lee and Ready (1991) as trade classification rule. As in the SSE case, the overall WPC of small-size trades is downward biased both in 1995 and 2005, but the magnitude of the bias is smaller in US markets. The WPC bias is larger with consolidated (N/P/T/Q) trades and quotes (1995: $-12.35 \%$ to $-18.51 \%$; 2005: $-11.08 \%$ to $-16.78 \%$ ) than with just NYSE trades and quotes (1995: $-4.8 \%$ to $-5.38 \% ; 2005$ : $-7.77 \%$ to $-12.83 \%$ ). Markedly, the friction-related bias has not vanished with the fall in the trade size lower bound for stealth trading during the 2000s.

As in the SSE case, we test the statistical significance of the bias for each trade-size category using Eq. (6). We report the estimated $\alpha, \beta_{1}$, and $\beta_{2}$ coefficients in Table 10 . We find positive and statistically significant (at the $1 \%$ level) $\beta_{1}$ and $\beta_{2}$ coefficients across the

\footnotetext{
24 Holden and Jacobsen (2014) show that the proliferation of fleeting orders and the TAQ treatment of millisecond time stamps cause significant distortions in methodologies that rely in the alignment of trades and quotes. Trade classification algorithms are a notorious example (e.g., Odders-White, 2000). Recently, Easley, López de Prado, and O'Hara (2013) argue that the growing speed, volume and fragmentation of current US markets pose serious challenges to traditional classification algorithms.

${ }^{25}$ We discard data from other exchanges. They represent $4.4 \%$ of all trades in 2005 and $22 \%$ in 1995.

${ }^{26}$ We obtain similar results with a 1 -second trade reporting lag. In the 1980 s and early 1990 s, the rule was to allow for a 5 -second trade reporting lag (e.g., Lee \& Ready, 1991). Using 1998 data, Bessembinder (2003) concludes the 5-second rule is no longer necessary. Since then, the common practice is the one we follow (e.g., Hendershott \& Moulton, 2011)

27 Odders-White (2000), Chakrabarty, Li, Nguyen, and Van Ness (2007), Easley et al. (2013), and Chakrabarty et al. (2014) offer reviews of trade classification algorithms.

${ }^{28}$ For NASDAQ-listed stocks, O'Hara et al. (2014) report a 60.9\% WPC for 2008-2010 trades with size [100, 500) (Table 6, Panel B), whilst Choe and Hansch (2005) report a 77.5\% WPC for 2000-2003 trades and a - 1\% WPC for 1993-1996 trades with size [100, 500) (Table 1).
} 


\section{Table 10}

US markets.

In this table, we provide the weighted price contribution (WPC) analysis for two samples of 150 US common stocks listed in the NYSE in 1995 (Panel A) and 2005 (Panel B), respectively. We use data from the NYSE Monthly TAQ. We consider BW93's trade-size classification: (0-499] small-sized, [500-9,999] medium-sized, [10,000 $\infty)$ large-sized. For each category, we report the friction-related bias in WPC, the proportion of trades (\%T), and the proportion of volume in shares (\%). The bias is computed as the difference between the WPC computed using trade-price changes and the friction-free WPC, computed using friction-unrelated changes in the quote midpoint. We report results for two different subsets of trades and quotes: 'N/P/T/Q NBBO' means consolidated data from the NYSE, Pacific Exchange/Arca and NASDAQ; 'NYSE BBO' means NYSE data only. Finally, we report the estimated $\alpha$ (small-size trades), $\beta_{1}$ (medium-size trades) and $\beta_{2}$ (large-size trades) coefficients of the Eq. (8).

\begin{tabular}{|c|c|c|c|c|c|c|c|c|c|c|c|}
\hline \multirow[t]{2}{*}{ Sample } & \multirow[t]{2}{*}{ Size category } & \multicolumn{5}{|c|}{ N/P/T/Q NBBO } & \multicolumn{5}{|c|}{ NYSE BBO } \\
\hline & & WPC & Bias $\ddagger$ & Coef. & $\% \mathrm{~T}$ & $\% \mathrm{~V}$ & NYSE & Bias $\ddagger$ & Coef. & $\% \mathrm{~T}$ & $\% \mathrm{~V}$ \\
\hline \multicolumn{12}{|c|}{ Panel A: 1995 data } \\
\hline \multirow[t]{3}{*}{ All days } & (0 499] & 11.54 & -18.51 & $-0.351^{* *}$ & 43.43 & 7.16 & 19.18 & -5.38 & $-0.069^{*}$ & 38.10 & 6.21 \\
\hline & [500 9,999] & 70.16 & 13.71 & $0.295^{* *}$ & 51.81 & 55.98 & 63.40 & 5.11 & $0.078^{* *}$ & 56.05 & 56.07 \\
\hline & {$[10,000 \infty)$} & 18.30 & 4.81 & $0.303^{* *}$ & 4.77 & 36.85 & 17.42 & 0.27 & $0.103^{* *}$ & 5.84 & 37.73 \\
\hline \multirow[t]{3}{*}{$R>1 \%$} & (0 499] & 14.63 & -12.35 & $-0.245^{* *}$ & 41.59 & 6.50 & 18.21 & -4.80 & -0.024 & 36.51 & 5.64 \\
\hline & [500 9,999] & 66.98 & 7.16 & $0.230^{* *}$ & 53.49 & 55.99 & 64.66 & 4.13 & $0.061^{* *}$ & 57.45 & 55.95 \\
\hline & {$[10,000 \infty)$} & 18.39 & 5.19 & $0.219^{* *}$ & 4.93 & 37.50 & 17.13 & 0.66 & $0.039^{* *}$ & 6.04 & 38.42 \\
\hline \multicolumn{12}{|c|}{ Panel B: 2005 data } \\
\hline \multirow[t]{3}{*}{ All days } & (0 499] & 60.23 & -11.08 & -0.166 & 77.98 & 38.96 & 57.65 & -7.77 & -0.094 & 75.63 & 38.31 \\
\hline & [500 9,999] & 35.50 & 9.46 & $0.195^{* *}$ & 21.63 & 49.16 & 37.42 & 9.36 & $0.083^{* *}$ & 23.84 & 51.20 \\
\hline & {$[10,000 \infty)$} & 4.27 & 1.62 & $0.115^{* *}$ & 0.39 & 11.88 & 4.93 & -1.59 & $0.032^{*}$ & 0.53 & 10.49 \\
\hline \multirow[t]{3}{*}{$\mathrm{R}>1 \%$} & (0 499] & 48.53 & -16.78 & -0.153 & 76.32 & 35.94 & 32.22 & -12.83 & $-0.460 * *$ & 73.76 & 35.29 \\
\hline & [500 9,999] & 44.66 & 14.96 & $0.492^{* *}$ & 23.18 & 50.17 & 57.74 & 15.06 & $0.767^{* *}$ & 25.54 & 52.09 \\
\hline & {$[10,000 \infty)$} & 6.81 & 1.82 & $0.310^{* *}$ & 0.50 & 13.89 & 10.04 & -2.23 & $0.437^{* *}$ & 0.70 & 12.62 \\
\hline
\end{tabular}

† Us ing Lee and Ready (1991).

${ }^{*}(* *)$ means p-value $<0.05(0.01)$.

board, corroborating the upward bias WPC for medium- and large-size trades. $\beta_{1}$ and $\beta_{2}$ tend to be larger using the NBBO than the NYSE BBO. The small-size trades' coefficient $(\alpha)$ is negative and highly significant for the 1995 consolidated trades and quotes. For the 2005 sample, the sign of $\alpha$ is consistent with the downward bias in WPC but only significant with NYSE BBO and on days with strictly positive returns.

\section{Summary and conclusions}

Introduced by Barclay and Warner (1993), the WPC approach has been extensively used to evaluate strategic fragmentation of orders and price leadership. Recently, van Bommel (2011) uses simulated data to question the unbiasedness of the WPC approach in the presence of serial correlation in the price changes. van Bommel focuses on the use of the WPC in low-frequency analyses about price leadership. In this paper, we extend this line of research. Firstly, we introduce a simple methodology to obtain friction-free WPC estimates using high-frequency data. Secondly, we generalize van Bommel's result by showing that the WPC approach generates biased estimates in the presence of a general friction-related component in price changes.

Our friction-free WPC approach ( $\overline{\text { WPC }}$ ), builds on Hasbrouck (1991). In a first step, we use quote midpoints instead of trade prices to get rid of the bid-ask bounce effect. In a second step, we use a time-series econometric model to extract the friction-related dynamics in the time series of the quote midpoint change. The resulting times series of friction-free quote midpoint changes is then used to compute the $\overline{\mathrm{WPC}}$.

To illustrate the usefulness of our approach, we study strategic fragmentation of orders in the electronic trading platform of the SSE

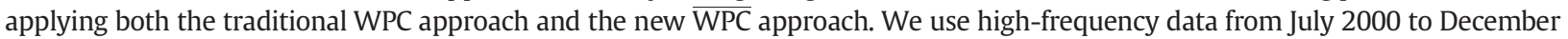
2006. We report a significant $-38.7 \%$ friction-related bias in the WPC of small-size trades in the SSE. The bias increases to $-72.71 \%$ if we restrict our analysis to days with open-to-close returns above $1 \%$. We therefore show that the WPC is not robust to trading frictions and the bias is more notorious when stealth trading is more likely to occur.

Most of the friction-related bias (85.6\%) is driven by the bid-ask bounce, but bid-ask-bounce-unrelated serial correlation markedly adds to the bias. Therefore, although replacing price changes by quote midpoint changes may correct most of the friction-related bias, the $\overline{\mathrm{WPC}}$ approach guarantees more precise estimates. Moreover, the magnitude of the bias depends on the time resolution of the WPC analysis. In contrast, the $\overline{\text { WPC }}$ estimates obtained for alternative time resolutions are alike.

We show that negative WPCs for small-size trades, commonly found in US and non-US studies during the 80s and 90s, can be attributed to trading frictions rather than underperformance by retail traders, as it is often assumed. We also document that the frictionrelated bias can distort formal tests of the stealth trading hypothesis.

We study the role that trade-aggressiveness plays in explaining the downward bias in the WPC of small-size trades in the SSE. We find that non-aggressive trades, which are more common among small size trades, frequently add noise to the WPC. In fact, the downward bias only affects to small-size non-aggressive trades ( $-49.1 \%)$. In days with strictly positive returns, small- and medium-size aggressive trades disproportionally contribute to price discovery.

Finally, we show that the friction-related bias in WPC is not market-specific. Using 1995 and 2005 NYSE-listed US stocks, we find a downward-biased WPC for small-size trades, but of smaller magnitude than for the SSE. The bias is larger if we use consolidated trades 
and quotes rather than NYSE trades and quotes alone. Because of inherent limitations of the Monthly TAQ database, however, we must treat the US findings with caution.

\section{Acknowledgements}

We would like to thank Carl R. Chen (the Editor), Douglas Cumming, Vicente Medina, Maria Rodriguez-Moreno, Heather Tookes, Terry Walter, Charles Schnitzlein and an anonymous referee for their insightful discussions. We are indebted to participants at the Infinity Conference on International Finance, Dublin (Ireland), June 2011; the 20th European Financial Management Association (EFMA) Annual Meetings, Braga (Portugal), June 2011; the XX Finance Forum, Oviedo (Spain), November 2012, and the Eastern Finance Association Meetings, Boston (USA), April 2012, for valuable comments on preliminary versions of the paper. We are grateful to Sociedad de Bolsas and BME for providing the database. We acknowledge the financial support of the Spanish projects ECO2010-18567 and ECO2011-29751. Earlier versions of this paper were completed while Roberto Pascual was a Visiting Fellow at the International Center for Finance of the Yale School of Management, New Haven, Connecticut. Any errors are entirely our own.

\section{References}

Abad, D., \& Pascual, R. (2010). Switching to a temporary call auction in times of high uncertainty. Journal of Financial Research, 33 , 45-75.

Admati, A.R., \& Pfleiderer, P. (1988). A theory of intraday trading patterns: Volume and price variability. Review of Financial Studies, 1, 3-40.

Ascioglu, A., Comerton-Forde, C., \& McInish, T.H. (2011). Stealth trading: The case of the Tokyo Stock Exchange. Pacific-Basin Finance Journal, $19,194-207$.

Bacidore, J., Ross, K., \& Sofianos, G. (2003). Quantifying market order execution quality at the New York Stock Exchange. Journal of Financial Markets, 6, 281-307.

Barber, B.M., \& Odean, T. (2000). Trading is hazardous to your wealth: The common stock investment performance of individual investors. Journal of Finance, 55, 773-806.

Barclay, M.J., \& Hendershott, T. (2003). Price discovery and trading after hours. Review of Financial Studies, 16, 1041-1073.

Barclay, M.J., \& Hendershott, T. (2008). A comparison of trading and non-trading mechanisms for price discovery. Journal of Empirical Finance, 15, 839-849.

Barclay, M.J., \& Warner, J.B. (1993). Stealth trading and volatility: Which trades move prices? Journal of Financial Economics, 34, $281-305$.

Bessembinder, H. (2003). Issues in assessing trade execution costs. Journal of Financial Markets, 6, 233-257.

Bessembinder, H., Panayides, M., \& Venkataraman, K. (2009). Hidden liquidity: an analysis of order exposure strategies in electronic stock markets. Journal of Financial Economics, 94, 361-383.

Biais, B., Hillion, P., \& Spatt, C. (1995). An empirical analysis of the limit order book and the order flow in the Paris Bourse. Journal of Finance, 50, 1655-1689.

Blau, B.M., Van Ness, B.F., \& Van Ness, R.A. (2009a). Intraday stealth trading: which trades move prices during periods of high volume? Journal of Financial Research, 32, $1-21$.

Blau, B.M., Van Ness, B.F., \& Van Ness, R.A. (2009b). Information and trade sizes: The case of short sales. Quarterly Review of Economics and Finance, 49, 1371-1388.

Cai, B.M., Cai, C.X., \& Keasey, K. (2006). Which trades move prices in emerging markets?: Evidence from China's stock market. Pacific-Basin Finance Journal, 14, 453-466.

Cao, C., Ghysels, E., \& Hatheway, F. (2000). Price discovery without trading: evidence from the Nasdaq pre-opening. Journal of Finance, 55, 1339-1365.

Chakrabarty, B., Li, B., Nguyen, V., \& Van Ness, R. (2007). Trade classification algorithms for electronic communications network trades. Journal of Banking and Finance, 31, 3806-3821.

Chakrabarty, B., \& Moulton, P.C. (2012). Earnings announcements and attention constraints. Journal of Accounting and Economics, 52, 612-634.

Chakrabarty, B., Pascual, R., \& Shkilko, A. (2014). Evaluating trade classification algorithms: Bulk volume classification versus the tick rule and the Lee-ready algorithm. SSRN Working Paper Series.

Chakravarty, S. (2001). Stealth trading: Which traders' trades move stock prices? Journal of Financial Economics, 61, $289-307$.

Chakravarty, S., Chiyachantana, C.N., \& Jiang, C. (2008). Earnings surprises and stealth trading. In F.S. Lhabitant, \& G.N. Gregoriou (Eds.), Stock market liquidity: Implications for market microstructure and asset pricing. New York: John Wiley and Sons.

Chakravarty, S., Van Ness, B.F., \& Van Ness, R.A. (2005). The effect of decimalization on trade size and adverse selection costs. Journal of Business, Finance and Accounting, $32,1063-1081$

Choe, H., \& Hansch, O. (2005). Which trades move stock prices in the internet age? Working paper. Pennsylvania State University.

Chung, K.H., Chuwonganant, C., \& McCormick, D.T. (2004). Order preferencing and market quality on NASDAQ before and after decimalization. Journal of Financial Economics, 71, 581-612.

Copeland, T.E., \& Galai, D. (1983). Information effects on the Bid-Ask spread. Journal of Finance, 38, 1457-1469.

Dufour, A., \& Engle, R.F. (2000). Time and the price impact of a trade. Journal of Finance, 55, 2467-2498.

Easley, D., López de Prado, M., \& O’Hara, M. (2013). Bulk classification of trading activity. Johnson school research paper series \#8-2012.

Easley, D., \& O'Hara, M. (1992). Time and the process of security price adjustment. Journal of Finance, 47, 577-605.

Ellis, K., Michaely, R., \& O'Hara, M. (2000). The accuracy of trade classification rules: Evidence from Nasdaq. Journal of Financial and Quantitative Analysis, 35, 529-551.

Ellul, A., Shin, H., \& Tonks, I. (2005). Opening and closing the market: Evidence from the London stock exchange. Journal of Financial and Quantitative Analysis, 40, 779-801.

Foucault, T., Moinas, S., \& Theissen, E. (2007). Does anonymity matter in electronic limit order markets? Review of Financial Studies, $20,1707-1747$.

Glosten, L.R. (1994). Is the electronic open limit order book inevitable? Journal of Finance, 49, 1127-1161.

Glosten, L.R., \& Milgrom, P.R. (1985). Bid, ask and transaction prices in specialist market with heterogeneously informed traders. Journal of Financial Economics, 14, 71-100.

Handa, P., Schwartz, R.A., \& Tiwari, A. (2003). Quote setting and price formation in an order driven market. Journal of Financial Markets, 6, 461-489.

Harris, L. (1998). Optimal dynamic order submission strategies in some stylized trading problems. Financial Markets, Institutions, and Instruments, 7, 26-74.

Hasbrouck, J. (1991). Measuring the information content of stock trades. Journal of Finance, 46, 179-207.

Hasbrouck, J. (1995). One security, many markets: Determining the contributions to price discovery. Journal of Finance, 50, 1175-1199.

Hasbrouck, J. (2007). Empirical market microstructure. Oxford University Press.

Hawkins, D.M. (1980). Identification of outliers. London: Chapman and Hall.

Hendershott, T., \& Moulton, P.C. (2011). Automation, speed, and stock market quality: The NYSE's hybrid. Journal of Financial Markets, $14,568-604$.

Holden, C., \& Jacobsen, S. (2014). Liquidity measurement problems in fast, competitive markets: Expensive and cheap solutions. Journal of Finance, 69, 1705-1745.

Huang, R.D. (2002). The quality of ECN and Nasdaq market maker quotes. Journal of Finance, 57, 1285-1319.

Kalev, P.S., \& Pham, L.T. (2009). Intraweek and intraday trade patterns and dynamics. Pacific-Basin Finance Journal, 17, $547-564$.

Kaniel, R., \& Liu, H. (2006). So what orders do informed traders use? Journal of Business, 79, 1867-1914.

Kyle, A.S. (1985). Continuous auctions and insider trading. Econometrica, 53, 1315-1335.

Lee, C.M.C., \& Ready, M. (1991). Inferring trade direction from intraday data. Journal of Finance, 46, 733-747.

Lin, Y. (2014). An empirical study on pre-trade transparency and intraday stealth trading. International Review of Economics and Finance, 30, $26-40$.

Menkhoff, L., \& Schmeling, M. (2010). Whose trades convey information? Evidence from a cross-section of trades. Journal of Financial Markets, $13,101-128$.

O'Hara, M., Yao, C., \& Ye, M. (2014). What's not there: Odd lots and market data. Journal of Finance, 69, 2199-2236. 
Odders-White, E. (2000). On the occurrence and consequences of inaccurate trade classification. Journal of Financial Markets, 3, $259-286$.

Pardo, A., \& Pascual, R. (2012). On the hidden side of liquidity. European Journal of Finance, 18, 949-967.

Pascual, R., \& Veredas, D. (2010). Does the open limit order book matter in explaining informational volatility? Journal of Financial Econometrics, 8, $57-87$.

Ranaldo, A. (2004). Order aggressiveness in limit order book markets. Journal of Financial Markets, 7, 53-74.

Smith, J.W. (1998). The effects of the order handling rules and 16ths on Nasdaq: a Cross-sectional analysis. NASD Working Paper 98-02.

Stoll, H.R. (2000). Presidential address: Friction. Journal of Finance, 55, 1479-1514.

Thompson, S. (2011). Simple formulas for standard errors that cluster by both firm and time. Journal of Financial Economics, 99, 1-10.

van Bommel, J. (2011). Measuring price discovery: The variance ratio, the $\mathrm{R}^{2}$, and the weighted price contribution. Finance Research Letters, 8 , $112-119$.

Wang, J., \& Yang, M. (2010). How well does the weighted price contribution measure price discovery? SSRN Working Paper.

White, H. (1980). A heteroskedasticity-consistent covariance matrix estimator and a direct test for hereroskedasticity. Econometrica, $48,817-838$. 